-研究报告・

\title{
西江中下游管的遗传多样性与种群动态历史
}

\author{
杨计平 ${ }^{1 \#}$ 李 策1,2\# 陈蔚涛 ${ }^{1}$ 李跃飞 ${ }^{1}$ 李新辉 ${ }^{*}$ \\ 1 (中国水产科学研究院珠江水产研究所, 广州 510380) \\ 2 (上海海洋大学海洋科学学院, 上海 201306)
}

摘要: 鳤(Ochetobius elongatus)曾经是我国许多河流的重要经济鱼类, 然而由于环境污染和人为干扰等原因, 鳤的 资源量萎缩严重, 种群处于极度濒危的境地。目前, 常规采样方法获得鲂样本的难度较大, 致使相关研究难以开展。 本研究通过仔鱼采集和成鱼采集的手段, 测定两个线粒体基因和两个核基因, 对西江中下游鲂的遗传多样性和种 群动态历史进行研究。结果显示, 西江中下游鲂的遗传多样性处于较低水平并且出现了衰退的迹象, 可能经历了遗 传瓶颈效应。此外，种群动态历史分析发现，西江中下游鲩在后更新世期间 $(0.06$ 和 0.13 百万年前) 经历了种群扩张， 刚好处于中更新世(0.78-0.126百万年前)冰期褪去之后, 表明更新世气候的波动影响了西江中下游鳤的种群动态。 作为鳤可能的重要产卵场，西江中下游部分江段可以考虑建立鳤的自然保护区，用于保育和修复鳤的种质资源。

关键词：鳤; 仔鱼采集; 线粒体基因和核基因; 种群扩张; 保护

\section{Genetic diversity and population demographic history of Ochetobius elongatus in the middle and lower reaches of the Xijiang River}

\author{
Jiping Yang ${ }^{1 \#}, \mathrm{Ce} \mathrm{Li}^{1,2 \#}$, Weitao Chen ${ }^{1}$, Yuefei $\mathrm{Li}^{1}$, Xinhui $\mathrm{Li}^{1^{*}}$ \\ 1 Pearl River Fisheries Research Institute, Chinese Academy of Fishery Science, Guangzhou 510380 \\ 2 College of Marine Sciences, Shanghai Ocean University, Shanghai 201306
}

\begin{abstract}
Ochetobius elongatus used to be an economically important fish species in many rivers of China. However, due to environmental destruction and human disturbance the resources of this fish species have reduced rapidly, and its populations are in a critically endangered condition. At present, it is very difficult to obtain specimens of O. elongatus, which limits research on this species. We obtained specimens of $O$. elongatus via larva and adult fish collection. Two mitochondrial genes and two nuclear genes were used to explore the genetic diversity and population demography of $O$. elongatus in middle and lower Xijiang River. Results showed that the genetic diversity of O. elongatus was low and is in recession, suggesting that $O$. elongatus might have undergone a genetic bottleneck event. Additionally, population demographic analyses revealed that $O$. elongatus population expanded during the Late Pleistocene (0.06 and 0.13 Million years ago), following the glacial retreat of the Middle Pleistocene glaciations (0.78-0.126 Million years ago). The results also revealed that Pleistocene climatic fluctuations have influenced the population demography of O. elongatus. Due to its potential as an important spawning ground for O. elongatus, sections of middle and lower Xijiang River should be considered as candidates for creating nature reserves to conserve and restore its genetic resources.
\end{abstract}

Key words: Ochetobius elongatus; larva fish collection; mitochondrial and nuclear genes; population expansion; conservation

鳤(Ochetobius elongatus)隶属于鲤形目鲤科鳤 属(Ochetobius), 分布于我国长江以南的众多河流 江段, 是当地重要的经济鱼类(乐佩琦, 2000)。鳤历 史上曾广泛分布于珠江水系的西江、东江、北江和
珠江三角洲地区(郑慈英, 1989)。然而，由于水利开 发和江河环境污染等的影响, 鲂的资源量萎缩极其 严重, 种群近乎濒危, 在珠江中下游甚至整个珠江 流域已有多年未被监测到(李捷等, 2010)。因此, 了

收稿日期: 2018-04-16 接受日期: 2018-06-01

基金项目: 中国水产科学研究院基本科研业务费(2016HY-ZC0503)

\# 同等贡献作者 Contributed equally to this work

* 通讯作者 Author for correspondence. E-mail: lxhui01@aliyun.com 
解这种濒危物种的遗传多样性现状对以后的管理 和保护策略的制定具有一定的指导意义。

由于难以获得样本, 目前关于鲩的研究胗胗无 几, 零星研究仅集中在大阶元的系统发育进化关系 (Wang et al, 2007; Tao et al, 2010)。本研究通过仔鱼 采集和室内培养的方法获得一定数量的样本, 加上 野外普查过程中采集的少量成鱼标本, 利用两个线 粒体基因和两个核基因对西江中下游鲩的遗传多 样性进行研究。此外, 还探讨了西江中下游管的种 群动态历史与更新世气候波动的关系, 以期对对鲩 的管理和保护提供参考。

\section{材料与方法}

\section{1 样品采集}

鲩样本主要来自仔鱼采集。仔鱼采样参照李 跃飞等(2012)的方法, 采样站位位于广东省肇庆 市渔政码头上游约 $50 \mathrm{~m}$ 处 $\left(23^{\circ} 05^{\prime} 06.24^{\prime \prime} \mathrm{N}\right.$, $112^{\circ} 23^{\prime} 40.13^{\prime \prime}$ E) (表1), 采样时间分别为2011年5月 和2013年5月。利用定置弶网进行多日多次采集, 每 天于早上、中午和晚上共采样3次, 每次采样 $2 \mathrm{~h}$ 。 弶网网口为 $1.5 \mathrm{~m} \times 1.0 \mathrm{~m}$ 的矩形, 网体呈四棱雉形, 雉体部分长 $6 \mathrm{~m}$, 后部与一个规格为 $0.8 \mathrm{~m} \times 0.4 \mathrm{~m} \times$ $0.4 \mathrm{~m}$ 的集苗箱相连, 网目为 $0.5 \mathrm{~mm}$, 网口逆水流方
向固定于离岸约 $10 \mathrm{~m}$ 的水中。采集到的仔稚鱼充氧 后带回实验室，根据鳤幼苗的早期形态特征进行初 步鉴定(梁秩栤等, 1985)。为了保证鉴定准确，经初 步䇻选的鲂幼苗在实验条件下投喂浮游动物培育。 培育时间均为 2 个月，一共获得鳤50尾，其中2011 年28尾, 2013年22尾。平均体长 $5.64 \pm 0.80 \mathrm{~cm}$, 平均 体重为 $1.62 \pm 0.57 \mathrm{~g}$, 易于进行形态鉴定。此外, 本 课题组于 2017年10月的野外调查中分别在广西壮 族自治区的桂平市和梧州市各采集管标本1尾(表1), 距离上次在珠江中下游渔业捕捞中监测到鲩已有 近10年之久。

\section{2 基因组DNA提取、扩增与测序}

采用高盐法提取基因组DNA，并利用 $1.2 \%$ 琼 脂糖凝胶电泳检测DNA质量。本研究分别选取了两 个线粒体基因和核基因。线粒体基因包括细胞色素 $b(C y t b)$ 和酰胺腺嘌呤二核苷酸 $(\mathrm{NADH})$ 脱氧酶亚单 位2 (ND2), 核基因包括肌球蛋白重链6 (myh6)和重 组激活基因2 (RAG2)。4个基因扩增与测序的引物信 息见表2。PCR反应体系为 $25 \mu \mathrm{L}$ : $2 \times \mathrm{PCR}$ mix $(0.1 \mathrm{U} / \mu \mathrm{L}) 12.5 \mu \mathrm{L}$, 正反向引物(10 mM) $1 \mu \mathrm{L}$, DNA 模板 $1 \mu \mathrm{L}$ ，最后用无菌水补齐至 $25 \mu \mathrm{L}$ 。Cytb和 $N D 2$ 的PCR反应条件为: $95^{\circ} \mathrm{C}$ 预变性 $3 \mathrm{~min}, 95^{\circ} \mathrm{C}$ 变性 $1 \mathrm{~min}, 58-64^{\circ} \mathrm{C}$ 退火 $1 \mathrm{~min}, 72^{\circ} \mathrm{C}$ 延伸 $1 \mathrm{~min}$; 运行30个

表1 本研究的采样信息

Table 1 Sample information of the present study

\begin{tabular}{lllll}
\hline 采样点 Sample site & 采样日期 Sampling time & 样本量 Sample size & 经度 Longitude & 纬度 Latitude \\
\hline 广西桂平 Guiping & 2017.09 & 1 & $110^{\circ} 05^{\prime} 54.78^{\prime \prime} \mathrm{E}$ & $23^{\circ} 24^{\prime} 08.25^{\prime \prime} \mathrm{N}$ \\
广西梧州 Wuzhou & 2017.09 & 1 & $111^{\circ} 17^{\prime} 15.32^{\prime \prime} \mathrm{E}$ & $23^{\circ} 28^{\prime} 07.94^{\prime \prime} \mathrm{N}$ \\
广东肇庆 Zhaoqing & 2011.05 & 22 & $112^{\circ} 23^{\prime} 40.13^{\prime \prime} \mathrm{E}$ & $23^{\circ} 05^{\prime} 06.24^{\prime \prime} \mathrm{N}$ \\
广东肇庆 Zhaoqing & 2013.05 & 28 & $112^{\circ} 23^{\prime} 40.13^{\prime \prime} \mathrm{E}$ & $23^{\circ} 05^{\prime} 06.24^{\prime \prime} \mathrm{N}$ \\
\hline
\end{tabular}

表2 本研究使用的引物信息

Table 2 Primer information used in the present study

\begin{tabular}{lllll}
\hline & 引物名 Primer & 引物序列 Primer sequence $\left(5^{\prime}-3^{\prime}\right)$ & 退火温度 Annealed temperature $\left({ }^{\circ} \mathrm{C}\right)$ & 参考文献 Reference \\
\hline Cytb & L14724 & GACTTGAAAAACCACCGTTG & $58-64$ & Xiao et al, 2001 \\
& H15915 & CTCCGATCTCCGGATTACAAGAC & & 黎瑞宝, 2013 $^{(1)}$ \\
ND2 & AFND2L & AAGCTYTYGGGCCCATACC & 58 & Chen et al, 2008 \\
& AFND2R & TCCYGCTTAGGGCTTTGAAGG & & Lovejoy \& Collette, 2001 \\
myh6 & myh6_F459 & CATMTTYTCCATCTCAGATAATGC & 53 & \\
& myh6_R1325 & ATTCTCACCACCATCCAGTTGAA & & 55 \\
\hline \multirow{2}{*}{ RAG2 } & RAG2-f2a & AARCGCTCMTGTCCMACTGG & 55 & \\
& RAG2-R6a & TGRTCCARGCAGAAGTACTTG & &
\end{tabular}

(1) 黎瑞宝 (2013) 中国海南鲌遗传多样性的比较研究. 硕士学位论文, 暨南大学, 广州. 
循环后, $72^{\circ} \mathrm{C}$ 延伸 $5 \mathrm{~min}$ 。myh6和 $R A G 2$ 的PCR反应条 件为: $95^{\circ} \mathrm{C}$ 预变性 $5 \mathrm{~min}, 95^{\circ} \mathrm{C}$ 变性 $1 \mathrm{~min}, 53^{\circ} \mathrm{C}-55^{\circ} \mathrm{C}$ 退火 $45 \mathrm{~s}, 72^{\circ} \mathrm{C}$ 延伸 $45 \mathrm{~s}$; 运行 35 个循环后, $72^{\circ} \mathrm{C}$ 延 伸10 min。PCR产物经1.2\%的琼脂糖凝胶电泳检测, 对于扩增效果良好的产物交由测序公司双向测序。

\section{3 数据处理与分析}

测序所得序列使用DNASTAR软件包(DNASTAR Inc., Madison, WI)来检测测序质量, 运行编辑 并生成一致序列。所得的一致序列使用MUSCLE (Edgar, 2004)进行比对, 然后剪掉首尾两端噪音序 列至同样长度。为了获得更多的变异信息, 分别合 并了两个线粒体基因和两个核基因用于后续分析。 线粒体DNA单倍型和核基因等位基因均使用DnaSP 5.10 (Librado \& Rozas, 2009)划分。利用DnaSP 5.10 统计每个基因的单倍型数, 并计算单倍型多样性 $\left(H_{d}\right)$ 、近期核苷酸多样性 $\left(\theta_{\pi}\right)$ 和历史核苷酸多样性 $\left(\theta_{w}\right)$ 。使用NETWORK 4.6 (Bandelt et al, 1999)构建 了Cytb、ND2和Cytb+ND2的单倍型中介网状图和 $m y h 6+R A G 2$ 的等位基因中介网状图。myh6和RAG2 由于变异位点不大于 3 个, 因此并未对这两个基因 单独进行等位基因中介网状图的构建。

本研究使用3种方法来研究鳤有效种群大小的 历史动态变化。(1)使用Arlequin 3.5 (Excoffier \& Lischer, 2010)计算Tajima's $D$ (Tajima, 1989)和Fu's Fs (Fu，1997)值来检验群体是否经历扩张。所有分 析均通过 1,000 次随机抽样交换检验参数显著性。(2) 利用错配分布 (mismatch distribution) (Rogers \& Harpending, 1992)来检验群体是否经历扩张。错配 分布分析用软件DnaSP5.10进行。(3)基于 4 个基因, 使用了一种非参数估计方法拓展贝叶斯天际线点 图(Extended Bayesian Skyline Plots, EBSP)来分析鳤 过去的群体数目的变化(Drummond et al, 2005)。

基于Mrmodeltest 2.3 (Nylander, 2004)计算每个 基因的最优核苷酸替代模型，使用BEAST v1.8.1 (Drummond \& Rambaut, 2007)软件中的贝叶斯马尔 可夫链的蒙特卡洛方法(Markov Chain Monte Carlo, $\mathrm{MCMC}$ )来进行EBSP分析。以Cytb进化速率作为指 定, 其他 3 个基因的进化速率由 Cytb进化速率估算 获得。鉴于鲤科鱼类每百万年 $1.0 \%-2.0 \%$ 的进化速 率(Meyer, 1993; Durand et al, 2002; Ketmaier et al, 2004), 因此本研究分别使用 $1.0 \%$ 和 $2.0 \%$ 每百万年 的进化速率来进行时间尺度的估算。EBSP采用严格
分子钟模型, 运行 $10^{9}$ 代, 每 1,000 代进行抽样, 舍弃 初始 $10^{8}$ 代。最后利用Tracer 1.5 (Rambaut \& Drummond, 2007)检验每个参数的稳定性状况。

\section{结果}

\section{1 序列信息}

本研究成功获得了 52 尾鲩的全部 4 个基因片 段。在序列两端截齐后, 共获得: (1) $895 \mathrm{bp}$ 的Cytb 序列, 其中包含了 19 个变异位点, 界定了 13 个单倍 型; (2) 977 bp 的ND2序列, 其中包含了12个变异位 点, 界定了17个单倍型; (3) $763 \mathrm{bp}$ 的myh6序列, 其 中包含了 1 个变异位点, 界定了 2 个等位基因; (4) $857 \mathrm{bp}$ 的RAG2序列, 其中包含了 3 个变异位点, 界 定了 3 个等位基因(图1)。在 4 个基因片段中均未发现 缺失和插入。合并后的线粒体基因和核基因分别界 定了 26 个单倍型和 5 个等位基因(图1)。

\section{2 遗传多样性}

基于 4 个基因和联合基因估算的单倍型数目、 单倍型多态性和核苷酸多态性见表3。基于线粒体 基因估算的单倍型多态性介于 $0.784-0.940$ 之间，近 期核苷酸多态性介于 $0.197 \%-0.239 \%$ 之间，历史核 苷酸多态性介于 $0.272 \%-0.470 \%$ 。基于核基因计算 的单倍型多态性、近期核苷酸多态性和历史核苷酸 多态性明显低于线粒体基因, 分别介于 $0.147-0.546$, $0.022 \%-0.060 \%$ 和 $0.029 \%-0.077 \%$, 这主要是由于 核基因进化速率较慢。此外，除了mhy6基因历史核 苷酸多态性小于近期核苷酸多态性外, 其他基因或 者基因组合的历史核苷酸多态性均大于近期核苷 酸多态性。

基于不同基因和基因组合构建的单倍型和等 位基因中介网状图表明, 西江中下游鳤并没有形成 显著的支系结构(图1)。从图1可以看出, 2011年和 2012年采集群体都检测到了私有单倍型：Cytb分别 检测到 8 个和 1 个私有单倍型, $N D 2$ 分别检测到 4 个和 7 个私有单倍型, $C y t b+N D 2$ 分别检测到 11 个和 9 个 私有单倍型, myh6 + RAG2分别检测到 2 个和 1 个私 有等位基因。

\section{3 种群动态历史}

由于核基因变异位点少，因此只对线粒体基因 进行了中性检验和错配分布分析。结果发现, Fu's $F s$ 在 Cytb, ND2和Cytb $+N D 2$ 都检测到显著的负值, 
Tajima’s $D$ 仅在 $C y t b$ 基因上得到了显著的负值(表3), 表明鲂发生了近期扩张。错配分布分析结果显示, 鲩在 $C y t b$ 和 $N D 2$ 上得到了单峰分布曲线, 在 $C y t b+$ $N D 2$ 上获得了多峰分布曲线(图2)。单峰分布曲线表
明群体经历了扩散。基于全部4个基因的EBSP分析 发现，西江中下游鲩在 0.13 百万年前(Ma) (基于 $C y t b$ 每百万年 $1.0 \%$ 的进化速率)和 $0.06 \mathrm{Ma}$ (基于 $C y t b$ 每百万年 $2.0 \%$ 的进化速率)发生了种群扩张(图3)。

表3 鳤遗传多样性指数、中性检验和最优核苷酸替代模型

Table 3 Genetic diversity indices, neutrality tests and optimal nucleotide substitution model of Ochetobius elongatus

\begin{tabular}{|c|c|c|c|c|c|c|c|}
\hline & $\begin{array}{l}\text { 单倍型数/个体数 } \\
\text { Number of haplotype/ } \\
\text { sample size }\end{array}$ & $\begin{array}{l}\text { 单倍型多态性 } \\
\text { Haplotype } \\
\text { diversity }\end{array}$ & $\begin{array}{l}\text { 近期核苷酸多态性 } \\
\text { Current nucleotide } \\
\text { diversity }\left(\theta_{\pi}, \%\right)\end{array}$ & $\begin{array}{l}\text { 历史核苷酸多态性 } \\
\text { Historical nucleotide } \\
\text { diversity }\left(\theta_{w}, \%\right)\end{array}$ & $\begin{array}{l}\text { Tajima's } \\
D \text { 检验 } \\
\text { Tajima's } D \text { test }\end{array}$ & $\begin{array}{l}\text { Fu's Fs检验 } \\
\text { Fu's Fs test }\end{array}$ & $\begin{array}{l}\text { 最优模型 } \\
\text { Optimal } \\
\text { model }\end{array}$ \\
\hline Cytb & $13 / 52$ & 0.784 & 0.197 & 0.470 & $-1.83^{* *}$ & $-5.43^{* *}$ & $\mathrm{HKY}+\mathrm{I}$ \\
\hline ND2 & $17 / 52$ & 0.869 & 0.239 & 0.272 & -0.35 & $-8.16^{* * *}$ & $\mathrm{~F} 81+\mathrm{I}+\mathrm{G}$ \\
\hline$C y t b+N D 2$ & $26 / 52$ & 0.940 & 0.219 & 0.366 & -1.33 & $-14.54^{* * *}$ & - \\
\hline myh6 & $2 / 52$ & 0.462 & 0.060 & 0.029 & - & - & HKY \\
\hline$R A G 2$ & $3 / 52$ & 0.147 & 0.022 & 0.077 & - & - & F81 \\
\hline myh6 + RAG2 & $5 / 52$ & 0.546 & 0.040 & 0.055 & - & - & - \\
\hline
\end{tabular}

** $P<0.01 ; * * * P<0.001$.

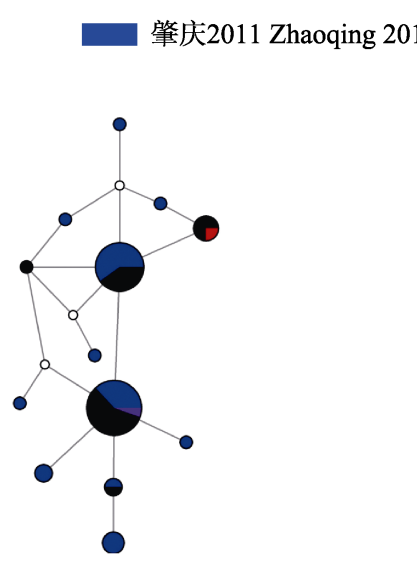

(a) Cytb

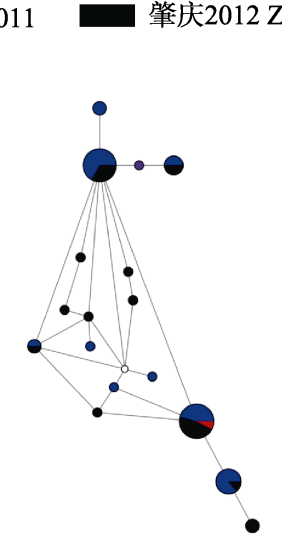

(b) ND2

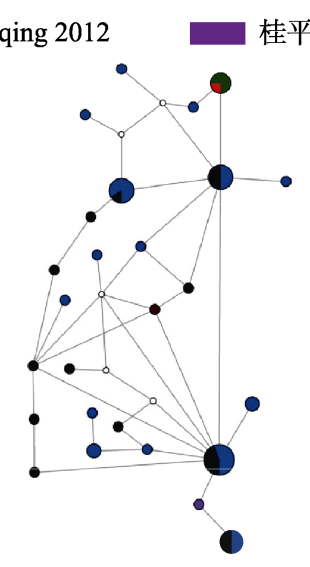

(c) $C y t b+N D 2$
梧州 Wuzhou

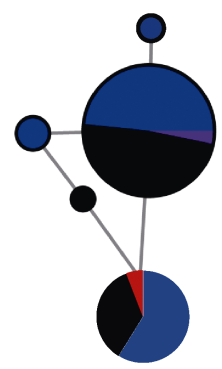

(d) $m y h 6+R A G 2$

图1 基于不同基因和基因组合的单倍型/等位基因中介网状图。白色圆圈表示缺失单倍型。

Fig. 1 Median-joining networks of haplotype and allele based on different genes and gene groups. White circles indicate missing haplotype.
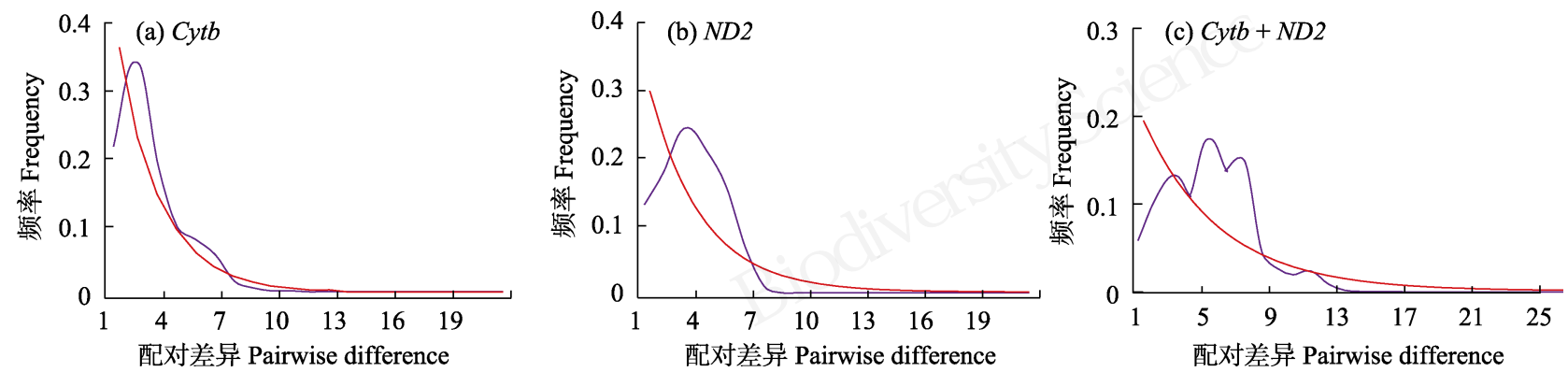

图2 基于不同基因和基因组合的错配分布分析。红色和紫色线条分别表示观测值和期望值。

Fig. 2 Mismatch distribution analysis based on different genes and gene groups. Red and purple lines represent observed value and expected values, respectively. 

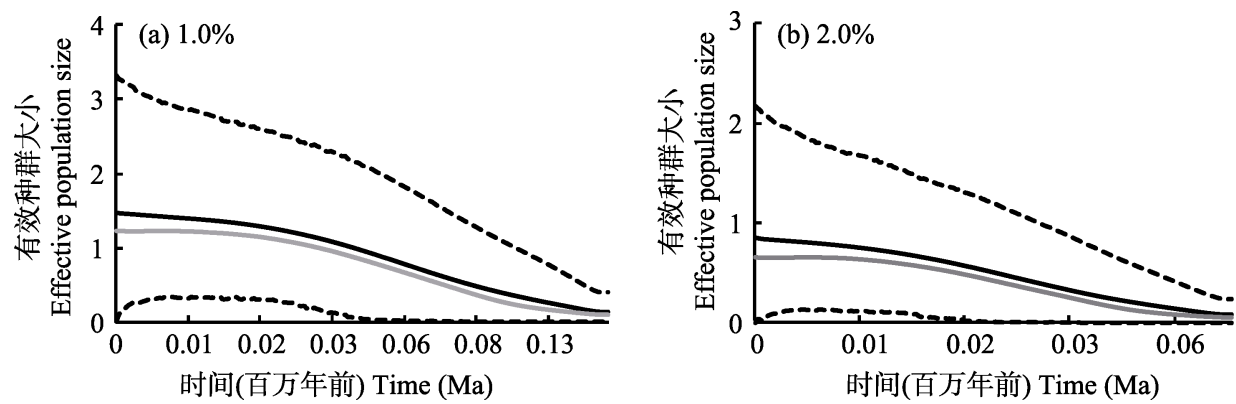

图3 拓展贝叶斯天际线点图(EBSP)。黑色实线表示有效种群大小的平均值, 灰色实线表示有效种群大小的中位数值, 虚线 表示 $95 \%$ 置信区间的有效种群大小。

Fig. 3 Extended Bayesian Skyline plots. Black lines represent mean values of effective population size, gray lines represent median values of effective population size, and dashed lines represent $95 \%$ confidence interval of effective population size.

\section{3 讨论}

\section{1 遗传多样性}

通过野外捕获鳤幼苗和实验室环境培育的方 法, 本研究在广东省西江肇庆江段一共获得了50尾 鳤样本。鳤产漂流性卵, 易随水流迁移扩散。研究 表明，漂流性鱼卵发育至幼苗阶段的累计漂流距离 可达几十至几百公里，甚至上千公里(Nesler et al, 1988; Tyus \& Haines, 1991; Araujo-Lima \& Oliveira, 1998; Zitek et al, 2004)。单倍型/等位基因中介网状 图也显示2011年和2012年的幼苗中均具有一定比 例的私有单倍型/等位基因, 表明鳤样本具有多个 亲本。因此，2011年5月和2012年5月在肇庆江段多 次采集的幼苗在一定程度上能够代表西江中下游 鲩的种质资源。

研究表明, 西江中下游管的遗传多样性呈现较 低的水平。作为曾经的重要经济鱼类, 鲩的核苷酸 多样性显著低于西江红水河江段鲢的核苷酸多样 性 $\left(\theta_{\pi}=0.36 \%-3.09 \%\right)$ (吴伟军等, 2015) 和长江流域 鳙的平均核苷酸多样性 $\left(\theta_{\pi}=0.80 \%\right)$ (李思发等, $1998)$, 但却显著高于珠江 $\left(\theta_{\pi}=0.104 \%\right)$ 、长江 $\left(\theta_{\pi}=\right.$ $0.092 \%)$ 和黑龙江 $\left(\theta_{\pi}=0.037 \%\right)$ 草鱼的核苷酸多样 性(朱叶, $2012^{\circledR}$ )以及珠江和长江青鱼的总核苷酸多 样性 $\left(\theta_{\pi}=0.159 \%\right.$ ) (付晓艳, $\left.2011^{2}\right)$ 。较高水平的单 倍型多态性(>0.5)和较低水平的核苷酸多态性(< 0.5\%)表明鳤可能在种群快速扩张和累积突变之后, 经历了种群的瓶颈效应(Grant \& Bowen, 1998)。自

(1) 朱叶 (2012) 基于线粒体细胞色素 $b$ 的三江水系草鱼群体遗传多样 性分析. 硕士学位论文, 暨南大学, 广州.

(2) 付晓艳 (2011) 长江和珠江水系青鱼线粒体细胞色素 $b$ 基因遗传多 样性分析. 硕士学位论文, 暨南大学, 广州.
第四纪以来, 我国华南地区在历史上经历了河流袭 夺、海水侵蚀、气候变化等系列地质事件(Gascoyne et al, 1979; 陈宜瑜等, 1986), 一定程度上改变了气 候和水域营养情况, 显著影响了鱼类的种群动态历 史。鳤作为肉食性鱼类, 易受到水体营养状况的影 响。本研究的中性检验、错配分布分析和EBSP分析 均证实西江中下游鳤经历了近期的种群扩张。此外, 由于水利开发、过度捕捞、江河水质污染等诸多原 因，导致鳤资源量急剧下降，近十年极少受其踪迹， 这也可能使鳤经历遗传瓶颈效应。基于多个基因和 基因组合估算的历史核苷酸多态性均大于近期核 苷酸多态性也证实了西江中下游鳤群体的遗传多 样性发生了显著的衰退。

\section{2 种群动态历史}

大量研究表明, 更新世气候的波动对许多动植 物的遗传多样性和分布格局产生了重要的影响 (Hewitt, 2004)。中性检验、错配分布分析和EBSP 分析均检测到西江中下游鳤经历近期种群扩张的 信号。基于 $1.0 \%$ 和 $2.0 \%$ 的进化速率估算出鳤发生种 群扩张分别发生在距今 $0.13 \mathrm{Ma}$ 和 $0.06 \mathrm{Ma}$, 刚好介 于后更新世期间(0.126-0.018 Ma)。我国华南地区在 中更新世期间(0.786-0.126 Ma) 经历了多次冰期 (Gascoyne et al, 1979), 气候变冷、海平面下降、食 物紧缺, 不利于生物的生存繁衍。冰期褪去后的间 冰期，即后更新世期间(0.126-0.018 Ma), 气候回暖, 海平面上升, 营养物质丰富, 大大促进了鲩的种群 扩张。因此, 更新世冰期与间冰期循环导致的气候 波动影响了西江中下游鲩的种群动态历史。

\section{3 保护建议}

目前, 鲩的资源量衰退极其严重, 在很多河流 
江段已多年未被监测到。在最新修订的《中国脊椎 动物红色名录》中, 鲩的保护等级已上升为极度濒 危(蒋志刚等, 2016)。本研究也表明西江中下游鲂的 遗传多样性发生了显著的衰退。稀缺的资源和较低 的遗传多样性使鳤极易受到环境变化等因素的影 响, 时刻面临灭绝的风险。种群动态历史分析发现 鲩易受到气候变化的影响, 因此鳤在全球气候变化 的大环境下更应该得到足够的重视。由于水利工程 建设一定程度上阻断了鲩的洄游路线, 过度捕捞则 直接导致鲩资源的减少, 因此过鱼通道的增设和禁 捕的相关规定很有必要。另外, 本研究组每年的仔 稚鱼普查中都在西江中下游发现一定数量的鲂幼 苗，这表明西江中下游是鲂在珠江水系比较重要的 产卵场。建议在西江中下游江段建立鳤的自然保护 区，用于保护和恢复鳤的种质资源。

\section{参考文献}

Araujo-Lima CARM, Oliveira EC (1998) Transport of larval fish in the Amazon. Journal of Fish Biology, 53, 297-306.

Bandelt HJ, Forster P, Rohl A (1999) Median-joining networks for inferring intraspecific phylogenies. Molecular Biology and Evolution, 16, 37-48.

Chen WJ, Miya M, Saitoh K, Mayden RL (2008) Phylogenetic utility of two existing and four novel nuclear gene loci in reconstructing Tree of Life of ray-finned fishes: The order Cypriniformes (Ostariophysi) as a case study. Gene, 423, 125-134.

Chen YY, Cao WX, Zheng CY (1986) Ichthyofauna of the Zhujiang River with a discussion on zoogeographical divisions for freshwater fishes. Acta Hydrobiologica Sinica, 10, 228-234. (in Chinese with English abstract) [陈宜瑜, 曹文 宣, 郑慈英 (1986) 珠江的鱼类区系及其动物地理区划 的讨论. 水生生物学报, 10, 228-234.]

Drummond AJ, Rambaut A (2007) BEAST: Bayesian evolutionary analysis by sampling trees. BMC Evolutionary Biology, 7, 214.

Drummond AJ, Rambaut A, Shapiro B, Pybus OG (2005) Bayesian coalescent inference of past population dynamics from molecular sequences. Molecular Biology and Evolution, 22, 1185-1192.

Durand JD, Tsigenopoulos CS, Unlu E, Berrebi P (2002) Phylogeny and biogeography of the family Cyprinidae in the Middle East inferred from cytochrome $b$ DNA-Evolutionary significance of this region. Molecular Phylogenetics and Evolution, 25, 91-100.

Edgar RC (2004) MUSCLE: Multiple sequence alignment with high accuracy and high throughput. Nucleic Acids Research, 32, 1792-1797.

Excoffier L, Lischer HEL (2010) Arlequin suite ver 3.5: A new series of programs to perform population genetics analyses under Linux and Windows. Molecular Ecology Resources, 10, 564-567.

Fu YX (1997) Statistical tests of neutrality of mutations against population growth, hitchhiking and background selection. Genetics, 147, 915-925.

Gascoyne M, Benjamin GJ, Schwarcz HP, Ford DC (1979) Sea-level lowering during the Illinoian glaciation: Evidence from a Bahama "blue hole”. Science, 205, 806-808.

Grant WS, Bowen BW (1998) Shallow population histories in deep evolutionary lineages of marine fishes: Insights from sardines and anchovies and lessons for conservation. Journal of Heredity, 89, 415-426.

Hewitt GM (2004) Genetic consequences of climatic oscillations in the Quaternary. Philosophical Transactions of the Royal Society B-Biological Sciences, 359, 183-195.

Jiang ZG, Jiang JP, Wang YZ, Zhang E, Zhang YY, Li LL, Xie F, Cai B, Cao L, Zheng GM, Dong L, Zhang ZW, Ding P, Luo ZH, Ding CQ, Ma ZJ, Tang SH, Cao WX, Li CW, Hu HJ, Ma Y, Wu Y, Wang YX, Zhou KY, Liu SY, Chen YY, Li JT, Feng ZJ, Wang Y, Wang B, Li C, Song XL, Cai L, Zang CX, Zeng Y, Meng ZB, Fang HX, Ping XG (2016) Red List of China's Vertebrates. Biodiversidy Science, 24, 500-551. [蒋志刚, 江建平, 王跃招, 张鹗, 张雁云, 李立 立, 谢锋, 蔡波, 曹亮, 郑光美, 董路, 张正旺, 丁平, 罗 振华, 丁长青, 马志军, 汤宋华, 曹文宣, 李春旺, 胡慧 建, 马勇, 吴毅, 王应祥, 周开亚, 刘少英, 陈跃英, 李家 堂 冯祚建, 王燕, 王斌, 李成, 宋雪琳, 蔡蕾, 蔵春金金, 曾岩, 孟智斌, 方红霞, 平晓鸽 (2016) 中国脊椎动物红 色名录. 生物多样性, 24, 500-551.]

Ketmaier V, Bianco PG, Cobollia M, Krivokapic M, Caniglia R, De Matthaeis E (2004) Molecular phylogeny of two lineages of Leuciscinae cyprinids (Telestes and Scardinius) from the peri-Mediterranean area based on cytochrome $b$ data. Molecular Phylogenetics and Evolution, 32, 1061-1071.

Li J, Li XH, Jia XP, Li YF, He MF, Tan XC, Wang C, Jiang WX (2010) Evolvement and diversity of fish community in Xijiang River. Journal of Fishery Sciences of China, 17, 298-311. (in Chinese with English abstract) [李捷, 李新辉, 贾晓平, 李跃飞, 何美峰, 谭细畅, 王超, 蒋万祥 (2010) 西江鱼类群落多样性及其演变. 中国水产科学, 17, 298-311.]

Li SF, Lü GQ, Bernatchez L (1998) Diversity of mitochondrial DNA in the populations of silver carp, bighead carp, grass carp and black carp in the middle- and lower reaches of the Yangtze River. Acta Zoologica Sinica, 44, 82-93. (in Chinese with English abstract) [李思发, 吕国庆, Bernatchez L (1998) 长江中下游鲢鳙草青四大家鱼线粒体DNA多样性 分析. 动物学报, 44, 82-93.]

Li YF, Li XH, Tan XC, Li J, Wang C (2012) Occurrence of larval Elopichthys bambusa and its relationship with hydrological conditions in the middle and lower reaches of Pearl 
River. Journal of Fisheries of China, 36(4), 15-22. (in Chinese with English abstract) [李跃飞, 李新辉, 谭细畅, 李 捷, 王超 (2012) 珠江中下游鳡鱼苗的发生及其与水文 环境的关系. 水产学报, 36, 15-22.]

Liang ZS, Mo RL, Chen FC (1985) Species identification and spawning type of common fish species in Xijiang River during early phase. In: The Report of Fishery Research in Pearl River Basin. Compilation Committee of Fishery Resources Survey of Pearl River Basin, Guangzhou. (in Chinese) [梁秩蓕, 莫瑞林, 陈福才 (1985) 西江常见鱼类早 期发育的分类鉴定及其产卵类型. 见: 珠江水系渔业资 源调查研究报告. 珠江水系渔业资源调查编委会, 广州.]

Librado P, Rozas J (2009) DnaSP v5: A software for comprehensive analysis of DNA polymorphism data. Bioinformatics, 25, 1451-1452.

Lovejoy NR, Collette BB (2001) Phylogenetic relationships of new world needlefishes (Teleostei: Belonidae) and the biogeography of transitions between marine and freshwater habitats. Copeia, 2001, 324-338.

Meyer A (1993) Evolution of Mitochondrial DNA in Fishes. Elsevier, The Hague.

Nesler TP, Muth RT, Wasowicz AF (1988) Evidence for baseline flow spikes as spawning cues for Colorado squawfish in the Yampa River, Colorado. In: American Fisheries Society Symposium, pp. 68-79. Bethesda, Maryland.

Nylander JAA (2004) MrModeltest v2. Evolutionary Biology Centre, Uppsala University, Uppsala.

Rambaut A, Drummond A (2007) Tracer v1.4. http://beast.bio. ed.ac.uk/Tracer. (accessed on 2018-3-2).

Rogers AR, Harpending H (1992) Population growth makes waves in the distribution of pairwise genetic differences. Molecular Biology and Evolution, 9, 552-569.

Tajima F (1989) The effect of change in population size on DNA polymorphism. Genetics, 123, 597-601.

Tao W, Zou M, Wang X, Gan X, Mayden RL, He S (2010)
Phylogenomic analysis resolves the formerly intractable adaptive diversification of the endemic clade of east Asian Cyprinidae (Cypriniformes). PLoS ONE, 5, e13508.

Tyus HM, Haines GB (1991) Distribution, habitat use, and growth of age-0 Colorado squawfish in the Green River basin, Colorado and Utah. Transactions of the American Fisheries Society, 120, 79-89.

Wang X, Li J, He S (2007) Molecular evidence for the monophyly of East Asian groups of Cyprinidae (Teleostei: Cypriniformes) derived from the nuclear recombination activating gene 2 sequences. Molecular Phylogenetics and Evolution, 42, 157-170.

Wu WJ, Peng M, Wang DP, Shi J, Li YS, Han YQ, Lei JJ, He AY (2015) Comparison of mitochondrial D-Loop and Cyt b sequences of Hypophthalmichthys molitrix. Open Journal of Fisheries Research, 2(4), 67-73. (in Chinese with English abstract) [吴伟军, 彭敏, 王大鹏, 施军, 李育森, 韩耀全, 雷建军, 何安尤 (2015) 红水河鲢线粒体D-Loop和Cyt b 基因序列分析. 水产研究, 2(4), 67-73.]

Xiao W, Zhang Y, Liu H (2001) Molecular systematics of Xenocyprinae (Teleostei: Cyprinidae): Taxonomy, biogeography, and coevolution of a special group restricted in East Asia. Molecular Phylogenetics and Evolution, 18, 163-173.

Yue PQ (2000) Fauna Sinica, Osteichthyes, Cypriniformes II Science Press, Beijing. (in Chinese) [乐佩琦 (2000) 中国 动物志. 硬骨鱼纲, 鲤形目, 中卷. 科学出版社, 北京.]

Zheng CY (1989) The Ichthyography of the Pearl River. Science Press, Beijing. (in Chinese) [郑慈英 (1989) 珠江鱼类 志. 科学出版社. 北京.]

Zitek A, Schmutz S, Unfer G, Ploner A (2004) Fish drift in a Danube sidearm-system: I. Site-, inter- and intraspecific patterns. Journal of Fish Biology, 65, 1319-1338.

(责任编委：何舜平 责任编辑：时意专) 